\title{
The dynamics of fish populations in the Palancar stream, a small tributary of the river Guadalquivir, Spain
}

\author{
Ramón Bravo*, Mila C. Soriguer, Noelia Villar, José A. Hernando \\ Departamento de Biología Animal, Biología Vegetal y Ecología, Facultad de Ciencias del Mar, \\ Universidad de Cádiz, Apdo. nº40, 11510 Puerto Real, Cádiz, Spain
}

Received 3 April 2000; revised 20 September 2000; accepted 20 November 2000

\begin{abstract}
The relationship between flooding and changes in the size distribution of fish populations in the Palancar stream confirms observations in other rivers. On average, density decreased by $36.2 \%$ and biomass increased by $14.5 \%$, passing from a period of severe drought to one of heavier than normal rains. Precipitation is the most important of the many factors affecting the populations of the Palancar stream; the most evident changes all occurred after the drought. During the drought period, the marked seasonal fluctuation in flow was the most important factor regulating the population dynamics. Fish density and biomass varied in proportion to the water volume. During the rainy period, the studied section of the river was found to be an important reproduction and nursery area, with juveniles and individuals of reproduction age dominating. The presence of Micropterus salmoides, an introduced piscivorous species, is another factor affecting the population dynamics in the Palancar stream. The observed absence of age 0+ individuals of the dominant populations is considered a direct effect of predation. (C) 2001 Éditions scientifiques et médicales Elsevier SAS
\end{abstract}

Barbus sclateri / biomass / Cobitis paludica / density / Leuciscus pyrenaicus

\section{INTRODUCTION}

There are many biological and environmental factors that regulate the dynamics of populations. Flow regime has a notable effect on the spatial and temporal distribution of fish communities [1,28]. Rivers in areas with Mediterranean-type climate, such as the Palancar stream, present patterns of water flow closely related to the regime of precipitation, even drying up in some years by the end of spring and early summer. This results in a considerably irregular flow, with winter floods alternating with periods of very low water [7], which influences the ecosystem and fish populations [16, 33].

From general considerations in fluvial systems with permanent flows, the 'River Continuum Concept' has been proposed as an integrating theory [32], but the validity of this concept in temporary rivers has been questioned by many authors $[3,16,26,35,36]$. From

*Correspondence and reprints: fax +34 956016019.

E-mail address: ramon.bravo@uca.es (R. Bravo). the degree of irregularity of its flow, the Palancar stream cannot be considered a continuous river.

The Palancar stream has a typical Mediterranean hydrological regimen, with a minimum flow in summer which increases gradually to a spring maximum. This flow irregularity has caused the fish communities to adapt their life strategies in respect to their life cycles $[8,9,29-31]$, their diet [12, 29] and migrations [24].

The understanding of the relationships between the fish communities and flow variations is of particular relevance for the management of Iberian rivers, since it has already been argued [15] that plans need to be put forward for the recovery of Mediterranean cyprinid species put at serious risk by the widespread destruction of their habitats.

The present study is one of several undertaken by the universities of Barcelona, Cádiz, Oviedo and Seville in collaboration with the Spanish National Museum of Natural Sciences (C.S.I.C.) on fish populations and communities in rivers of the Iberian Peninsula. The specific aim of this study is to deter- 
mine the factors that regulate the fish population dynamics in the Palancar stream, i.e. the factors controlling temporal variations in density and biomass. The study covered a period corresponding to the end of a long and severe drought, followed by heavy rains, which enabled us to assess the effects of such changes on fish populations, namely to identify modifications in the structure of the cyprinid populations, to quantify seasonal variations in density and biomass, and to determine the most important biological and environmental factors affecting them. Moreover, the impact of the recent introduction into the stream of an exotic piscivorous species, Micropterus salmoides has also been evaluated; this species is the only predator of importance among the fish populations of the Palancar stream, and the presence of other piscivorous vertebrates is rare. It was introduced without any prior evaluation or subsequent control. It is most likely that the commercial development of angling in the area was the motive behind its introduction.

\section{MATERIALS AND METHODS}

\subsection{Study area and period}

The Palancar stream is a secondary tributary of the middle course of the river Guadalquivir. It rises at about $900 \mathrm{~m}$ above sea level and flows for about $13 \mathrm{~km}$ before it joins the river Genilla. The study area is located in the Natural Park of the Subbetic mountain range, between $37^{\circ} 27^{\prime} 39^{\prime \prime}-37^{\circ} 28^{\prime} 3$ ' $\mathrm{N}$ and $4^{\circ} 17^{\prime} 15^{\prime}-4^{\circ} 18^{\prime} 10^{\prime \prime} \mathrm{W}$ (figure 1). After examining the entire course of the stream, a 100-m long stretch was selected as representative of the different types of habitat present in the stream (deeper pools, rapids, bank characteristics); the populations of cyprinids present also show well-defined structures in which individuals of all age classes were found.

To record site morphology, a bathymetric map was drawn. Water depth was measured at $25-\mathrm{cm}$ intervals along transects across the stream every $2 \mathrm{~m}$, and used to construct isobaths. Bottom structure and vegetation were also recorded along these transects. Measurements of physical and chemical variables were made, water samples were taken for subsequent laboratory analysis (table I).

Precipitation and temperature in the study area were described in ombrothermic diagrams, in which the end of the drought and the beginning of the rainy period can be clearly observed (figure 2).

Initially, it was proposed to undertake five seasonal samplings over the course of one full year, the first being made in the summer of 1994 and continuing through to the summer of 1995 , coinciding with the

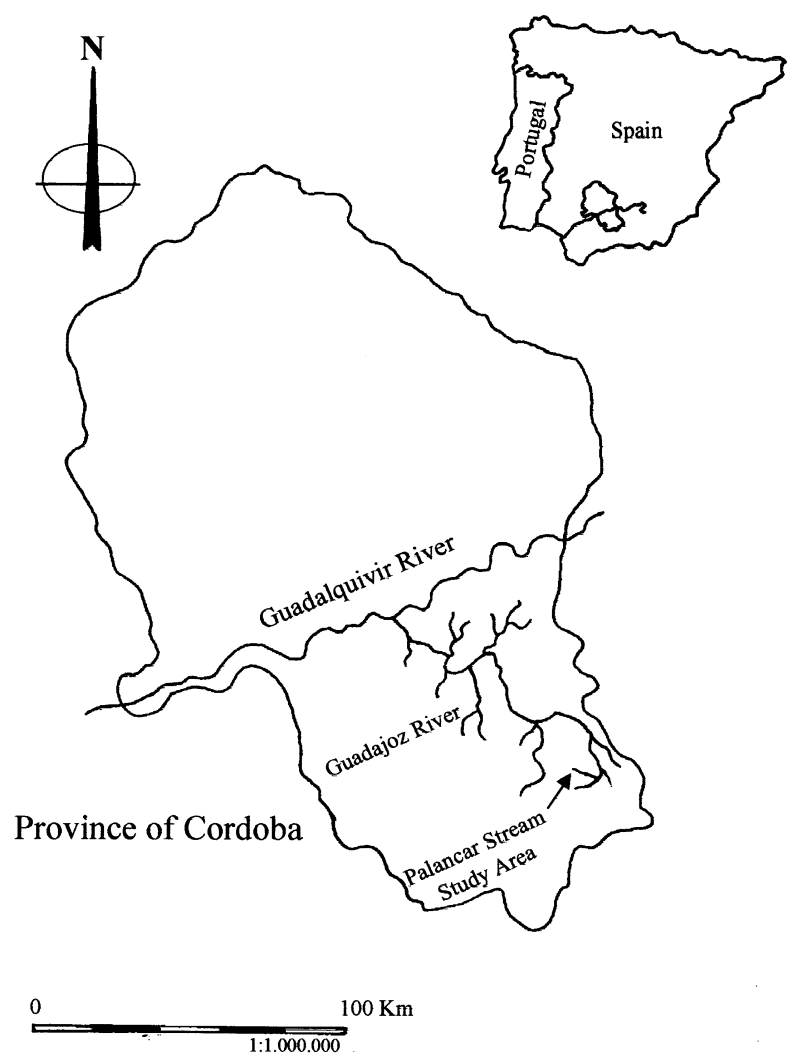

Figure 1. Map of location of the river Guadalquivir in the Iberian Peninsula and of the study sampling area in the Palancar stream.

last years of the most severe drought experienced in the south of the Iberian Peninsula in one hundred years. The climatic conditions changed radically in the autumn of 1995. On some days in October and November 1995 and in April and November 1996, the stream overflowed its banks so violently that it carried away trees from the banks, bridges and irrigation channels. It is assumed that the fish were also swept downstream because the velocity was such that they would be incapable of swimming against it or finding places to take refuge. It was decided to extend the study to another annual cycle under these new environmental conditions, with the aim of determining the responses of the populations to the changes. This second cycle covered the period from the summer of 1996 to the summer of 1997 , hence the seasonal samplings are discontinuous, with none taken in autumn and winter 1995 and spring 1996. The summer is an appropriate season for beginning and finishing the annual samplings because summer is when the reproductive processes have been concluded and the new recruits have been incorporated into the populations. 
Table I. Chemical characteristics of site $\left(\mathrm{mg} \cdot \mathrm{L}^{-1}\right)$. * Values not measured. The critical values are EU threshold values.

\begin{tabular}{|c|c|c|c|c|c|c|c|c|c|c|c|c|c|c|c|c|}
\hline $\begin{array}{l}\text { Sampling } \\
\text { Season }\end{array}$ & $\mathrm{Ca}^{2+}$ & $\mathrm{Mg}^{2+}$ & $\mathrm{K}^{+}$ & $\mathrm{Na}^{2+}$ & $\mathrm{NH}_{4}^{+}$ & $\mathrm{Cl}^{-}$ & $\mathrm{NO}_{3}{ }^{2-}$ & $\mathrm{NO}_{2}^{2-}$ & $\mathrm{SO}_{4}{ }^{2-}$ & $\mathrm{SiO}_{3}{ }^{2-}$ & $\mathrm{PO}_{4}{ }^{2-}$ & $\mathrm{HCO}_{3}^{-}$ & $\mathrm{CO}_{3}{ }^{2-}$ & $\mathrm{T}\left({ }^{\circ} \mathrm{C}\right)$ & $\mathrm{O}_{2}$ & $\mathrm{pH}$ \\
\hline Summer'94 & 201.64 & 38.05 & 1.28 & 14.6 & 0.047 & 13.17 & 7.26 & 0.06 & 377.17 & 12.12 & 0.027 & 237 & 3 & 15.5 & 7.9 & 8.18 \\
\hline Autumn'94 & 140.27 & 25.6 & 0.68 & 5.6 & 0.011 & 12.45 & 5.98 & 0.008 & 247.61 & 10.16 & 0.007 & 197.03 & 2.4 & 12.3 & 7.1 & 8.3 \\
\hline Winter'94 & 142.99 & 26.65 & 0.58 & 10.8 & 0.018 & 12.47 & 7.99 & 0.009 & 255.84 & 7.45 & 0.008 & 211.67 & 3 & 10.7 & 10 & 8.31 \\
\hline Spring'95 & 158.06 & 36.8 & 0.86 & 6.2 & 0.042 & 13.43 & 5.74 & 0.013 & 312.6 & 11.45 & 0.042 & 245.83 & 4.2 & 14 & 6.7 & 8.18 \\
\hline Summer'95 & 156.91 & 40.5 & 1.05 & 11.8 & 0.039 & 14.5 & 7.67 & 0.021 & 363.6 & 12.95 & 0.005 & 195.2 & 4.8 & 17.3 & 8 & 8.3 \\
\hline Summer'96 & 118.8 & 28.8 & 1.38 & 12.36 & 0.046 & 21 & 3.04 & 0.037 & * & 3.98 & 0.016 & 191.54 & 0.72 & 17 & 15.8 & 7.73 \\
\hline Autumn'96 & 115.6 & 25.2 & 1.14 & 5.15 & 0.019 & 14 & 3.04 & 0.016 & 205.11 & 2.53 & 0.03 & 153.11 & 0.6 & 11.1 & 8.1 & 7.6 \\
\hline Winter'96 & 95 & 18 & 0.86 & 7.21 & 0.024 & 14 & 3.03 & 0.015 & 155.75 & 1.67 & 0.01 & 29.28 & 0.3 & 13.5 & 10 & 7.86 \\
\hline Spring'97 & 171.08 & 32.87 & 4.3 & 37.83 & 0.013 & $*$ & 7.35 & 0.03 & 212.01 & 6.68 & 0.04 & 166.16 & 2.17 & 14.3 & 9 & 7.54 \\
\hline Summer'97 & 168.91 & 30.28 & 4.2 & 21.02 & 0.016 & $*$ & 6.42 & 0.018 & 258.03 & 7.42 & 0.05 & 225.52 & 2.2 & 17.5 & 8.1 & 7.32 \\
\hline Critical value & $\geq 200^{(1)}$ & $\geq 50$ & $\geq 12$ & $\geq 150$ & $\geq 5$ & $\geq 350$ & (2) & $\geq 0.04$ & $\geq 300^{(1)}$ & (1) (2) & $\geq 0.3$ & (1) (2) & (1) (2) & (3) & $<4$ & $(6,9)$ \\
\hline
\end{tabular}

(1) The levels depend on the type of substrate over which the river flows.

(2) No reference levels.

(3) Anomalies may exist in the water temperature as a result of discharges, which should not exceed $10{ }^{\circ} \mathrm{C}$. 


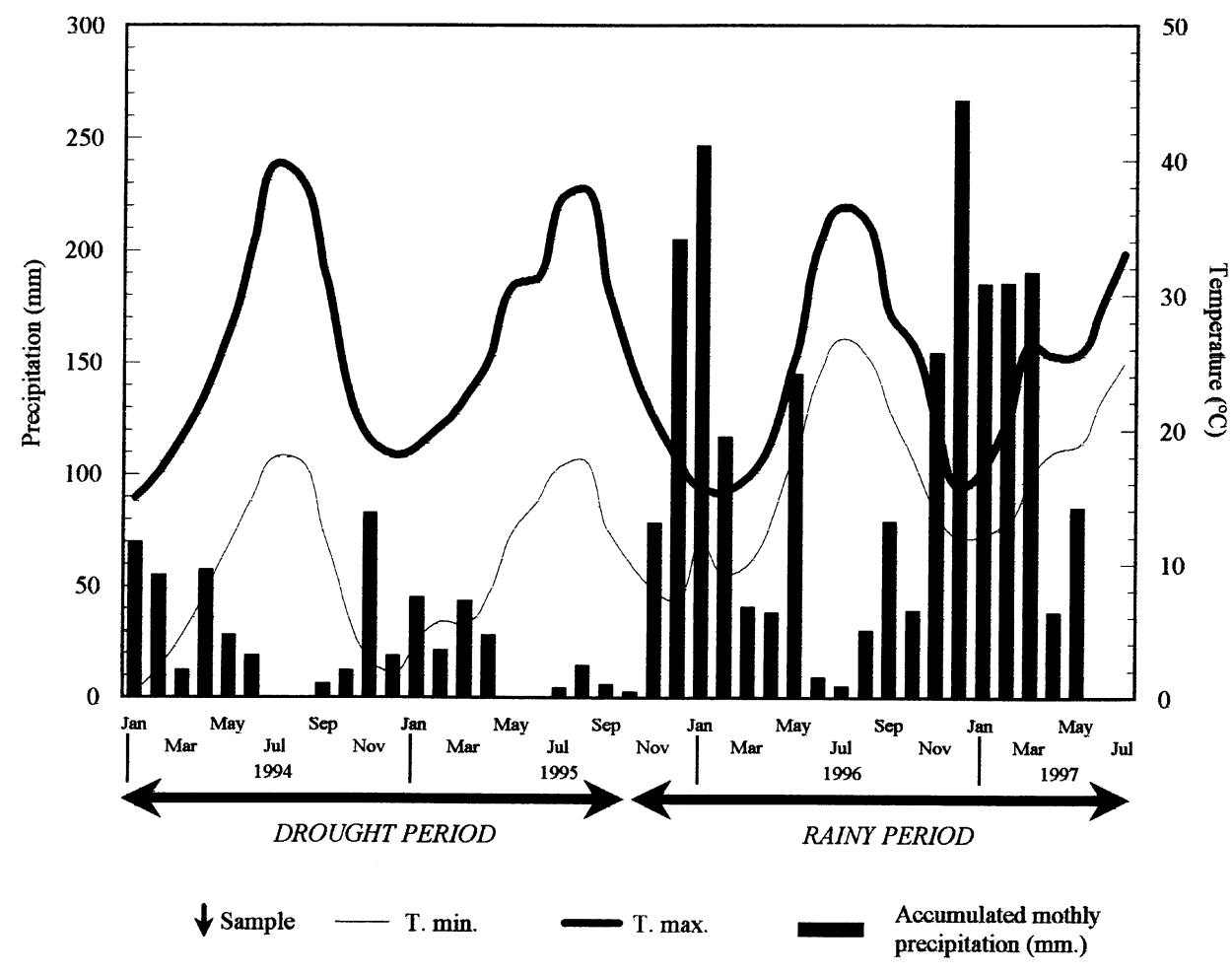

Figure 2. Ombrothermal diagram of the sampling area, showing the maximum and minimum air temperatures $\left({ }^{\circ} \mathrm{C}\right.$, right-hand scale), and rainfall per month $(\mathrm{mm}$, lefthand scale).

\subsection{Field and laboratory methods}

The simplified Zippin maximum-likelihood model for three removals $[23,37,38]$ was the method used to estimate fish abundance $(N)$. The methodology for sampling the fish populations was designed to meet the assumptions of this method, which are: (i) fish cannot move into or out of the sample area during the estimation period, hence a stop net $(2.5 \mathrm{~mm}$ diameter mesh) was placed at the downstream and upstream limits of the sample site; (ii) the fishing effort remains constant during the sampling, so three people waded upstream and electrofished with anode-dipnets for a constant time of $45 \mathrm{~min}$; (iii) all fish have an equal probability of capture; (iv) the catch efficiency $(p)$ is constant over all catches, which was confirmed using the chi-squared test $[13,27]$.

The equation used to calculate the standing crop $(B)$ was: $B=B_{t} \cdot N / C$, where $B_{t}$ is the total weight of fish caught and $C$ the total number of fish caught [14].

Over a year, monthly samples of fish were aged using scales [29] and to classify captured fish into age-groups, length-frequency histograms were used. These methods have been considered sufficiently accurate for this type of study [34]. The relationship between individual wet weight $(w)$ and total length $(T L)$ was used to calculate mean weight for every age-group: $w=\mathrm{a} \cdot T L^{\mathrm{b}}$, where $\mathrm{a}$ and $\mathrm{b}$ are constants determined by least squares regression (table II).

Table II. Relationship between total length $(T L, \mathrm{~mm})$ and body wet weight $(w, \mathrm{~g})$ of species from the Palancar Stream. The correlation coefficients $(r)$ for these relationships were significant (minimum at $P<0.001$ ). * Equations not calculated.

\begin{tabular}{lcccccc}
\hline & \multicolumn{2}{c}{ B. sclateri } & \multicolumn{2}{c}{ L. pyrenaicus } & & C. paludica \\
\hline Summer & $w=7.32 \cdot 10^{-6} T L^{3.087}$ & $r=0.982$ & $w=3.96 \cdot 10^{-6} T L^{3.267}$ & $r=0.970$ & $*$ & $*$ \\
Autumn & $w=6.56 \cdot 10^{-6} T L^{3.074}$ & $r=0.988$ & $w=5.18 \cdot 10^{-6} T L^{3.1169}$ & $r=0.918$ & $*$ & $*$ \\
Winter & $w=3.39 \cdot 10^{-6} T L^{3.042}$ & $r=0.964$ & $w=4.64 \cdot 10^{-6} T L^{3.188}$ & $r=0.991$ & $*$ & $*$ \\
Spring & $w=5.57 \cdot 10^{-6} T L^{3.106}$ & $r=0.997$ & $w=3.89 \cdot 10^{-6} T L^{3.274}$ & $r=0.984$ & $*$ & $*$ \\
Total & $*$ & $*$ & $*$ & $*$ & $w=9.04 \cdot 10^{-7} T L^{3.541}$ & $r=0.989$ \\
\hline
\end{tabular}


To study the seasonal changes in the population structure, cluster analyses were performed, using percentage of individuals calculated per age-group and sampling season as the variables. The clustering method used was the 'nearest neighbour' (single linkage), with squared Euclidean metric distance.

\section{RESULTS}

\subsection{General}

The physical and chemical quality of the water of the Palancar stream indicated an absence of pollution; ion concentrations were below the thresholds of standard values (78/659/CEE). There were no significant differences in water chemistry between the sampling stations (Kruskal-Wallis test, $P=0.986$ ). Precipitation during the drought was always less than $100 \mathrm{~mm} \cdot \mathrm{month}^{-1}$, and on occasions during the rainy period, it was more than $270 \mathrm{~mm} \cdot \mathrm{month}^{-1}$. The average daily precipitation during the dry and rainy periods was 27.3 and $92.1 \mathrm{~mm} \cdot \mathrm{month}^{-1}$, respectively.

The fish community of the Palancar stream comprises the following four species: Leuciscus pyrenaicus, Barbus sclateri, Cobitis paludica and Micropterus salmoides. The first three species are endemic to the southern half of the Iberian Peninsula and protected by the Berne Convention [2]; M. salmoides is endemic to North America; it was captured only in the last sampling, in summer 1997.

The population of $B$. sclateri reached the age-group $11+$, while $L$. pyrenaicus reached age-group $7+$, and $C$. paludica reached $5+$. For $M$. salmoides, only the age-groups $1+, 2+$ and $3+$ were captured. C. paludica and $M$. salmoides are not abundant and some agegroups were not present in samples. Given the situation for C. paludica and M. salmoides, this study is essentially based on the populations of B. sclateri and L. pyrenaicus.

\subsection{Barbus sclateri}

During the drought years, all age-groups of this species were found, with individuals of the age-groups $0+, 1+$ and $2+$ each normally representing more than $15 \%$ of the total. The average abundance found in these samplings was of 297 specimens. However, when the drought ended, the average abundance found was of 108 and the population structure underwent marked changes, such as the disappearance of agegroup $1+$ in the summer of 1996, after having been predominant the previous summer. In the summer of $1996,45.7 \%$ of the low total capture consisted of individuals of age-group $0+$, with no other age-group reaching $15 \%$. This general pattern was maintained in the autumn and winter of 1996 and in the spring of 1997 (another low total), in which the age-group 0+ represented $47.8,55.6$ and $22.4 \%$ of the total, respectively. Additionally, in these seasons, only the agegroups $6+$ and $7+$ in autumn 1996, the age-group $8+$ in winter 1996 and the age-groups 6+ and 8+ in spring 1997 exceeded $10 \%$. The structure showed a change in summer 1997, when the age-group 0+ reached only $2.7 \%$ of the total capture; the age-groups $1+(24.3 \%)$ and $5+(31.5 \%)$ were predominant; in the latter case, this was the first time that an age-group older than 4+ exceeded $15 \%$ (figure 3 ).

From the cluster analysis, three groups can be distinguished: group I is associated with the samplings during the drought, and group II with the samplings during the subsequent rainy period, except for the sampling made in summer 1997, which forms group III (figure 5a). On this basis, the existence of two different population structures was established, one corresponding to the drought and the other to the rainy period, while the third type of population structure observed in summer 1997 corresponded to neither period.

\subsection{Leuciscus pyrenaicus}

A similar situation is observed in the case of $L$. pyrenaicus. During the drought, average abundance was of 518 specimens and individuals from all agegroups were captured, but once the rainy period began, this situation changed: average abundance was of 401 and several age-groups were missing completely from the samples: no individuals were captured in the age-groups $1+$ and $2+$ in summer 1996, in age-groups $2+$ and $3+$ in autumn 1996, 2+, 3+ and 4+ in winter 1996, 4+ in spring 1997 and 0+, 4+ and 5+ in summer 1997.

In summer 1994, the age-groups $1+, 2+$ and $3+$, and in the remaining samplings the age-groups $0+$ and $1+$ were predominant. During the rainy period, this population structure changed, with increases in the percentage of individuals captured belonging to the three oldest age-groups. Hence in summer and autumn 1996, the predominant age-groups were $0+, 5+$ and $6+$; in winter 1996, 0+, 1+, 5+ and 6+ were predominant; in winter $1997,1+, 6+$ and $7+$; and, finally, in summer 1997, the age-groups $1+, 2+, 6+$ and $7+$. A considerable increase of the $0+$ age-group in summer and autumn 1996 was observed, representing 56.51 and $40.16 \%$, respectively, decreasing progressively until summer 1997. No individuals of this age-group were found. In addition, there was a large increase in the captures of the age-groups $6+$ and $7+$, from initial percentages of 3.2 and $0.27 \%$ in summer 1995, reaching 31.1 and $27.5 \%$ in summer 1997, respectively. This means that in the course of only 1 year, the 

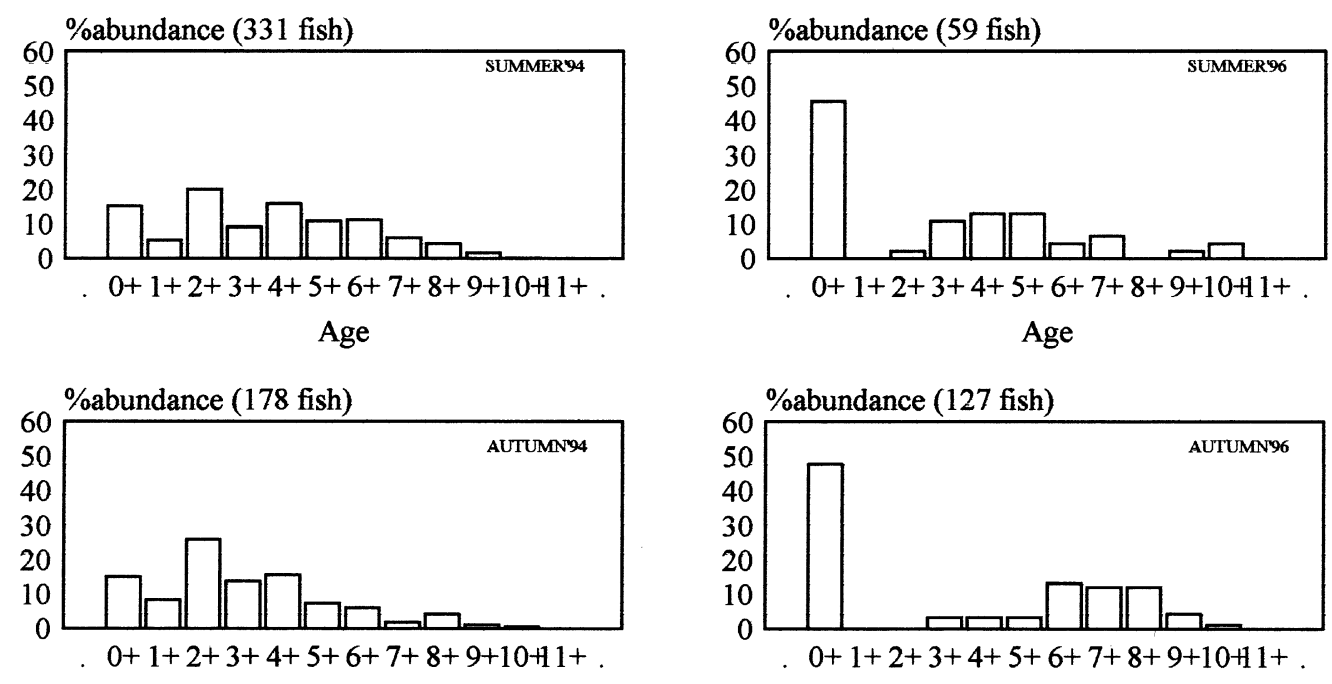

Age

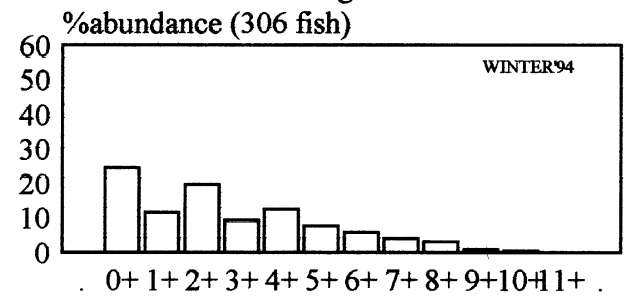

Age

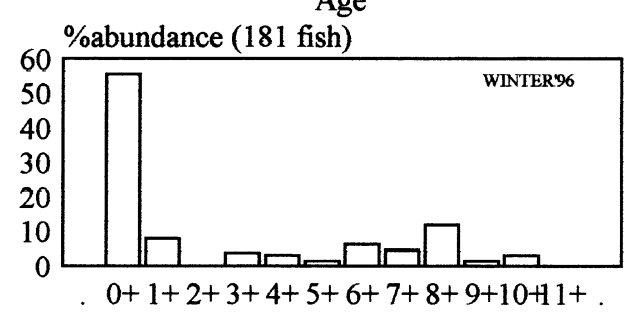

Age

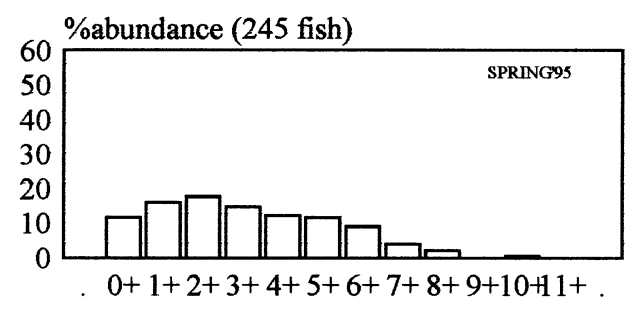

Age

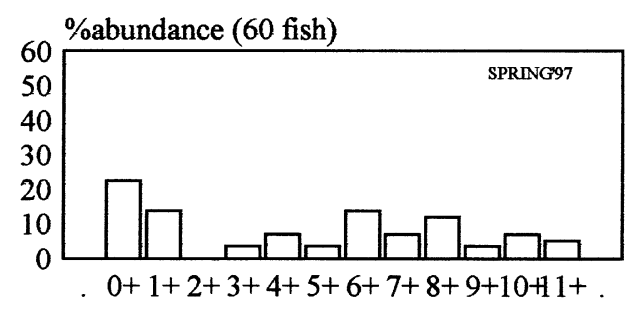

Age
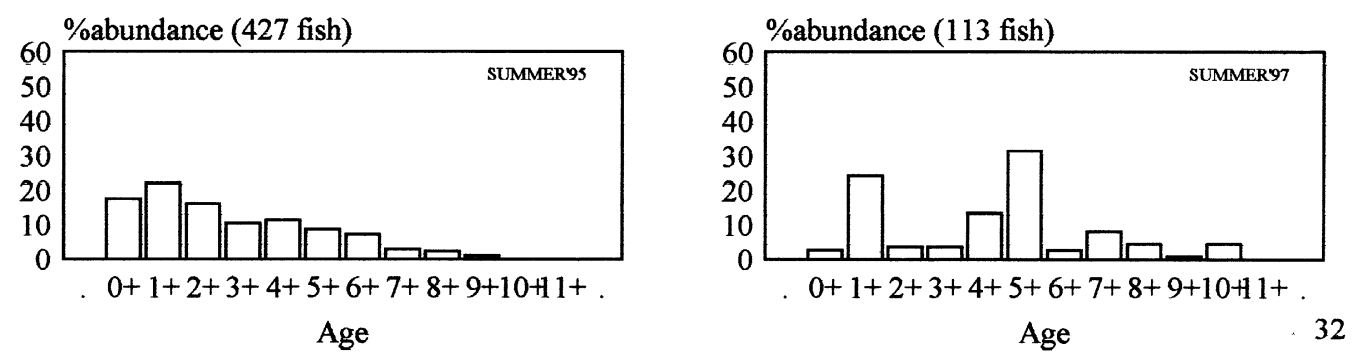

Figure 3. Frequency histogram of the percentage of abundance by age classes of the population of $B$. sclateri in the samplings made.

age-group 0+ disappeared, despite having formed over $50 \%$ of the population, whereas the two oldest agegroups showed capture percentages increased by a factor of ten (figure 4).
From the cluster analysis, three distinct groups were found as in B. sclateri. One group is formed by the samplings during the drought (group I) and another includes the samplings during the rainy period (group 

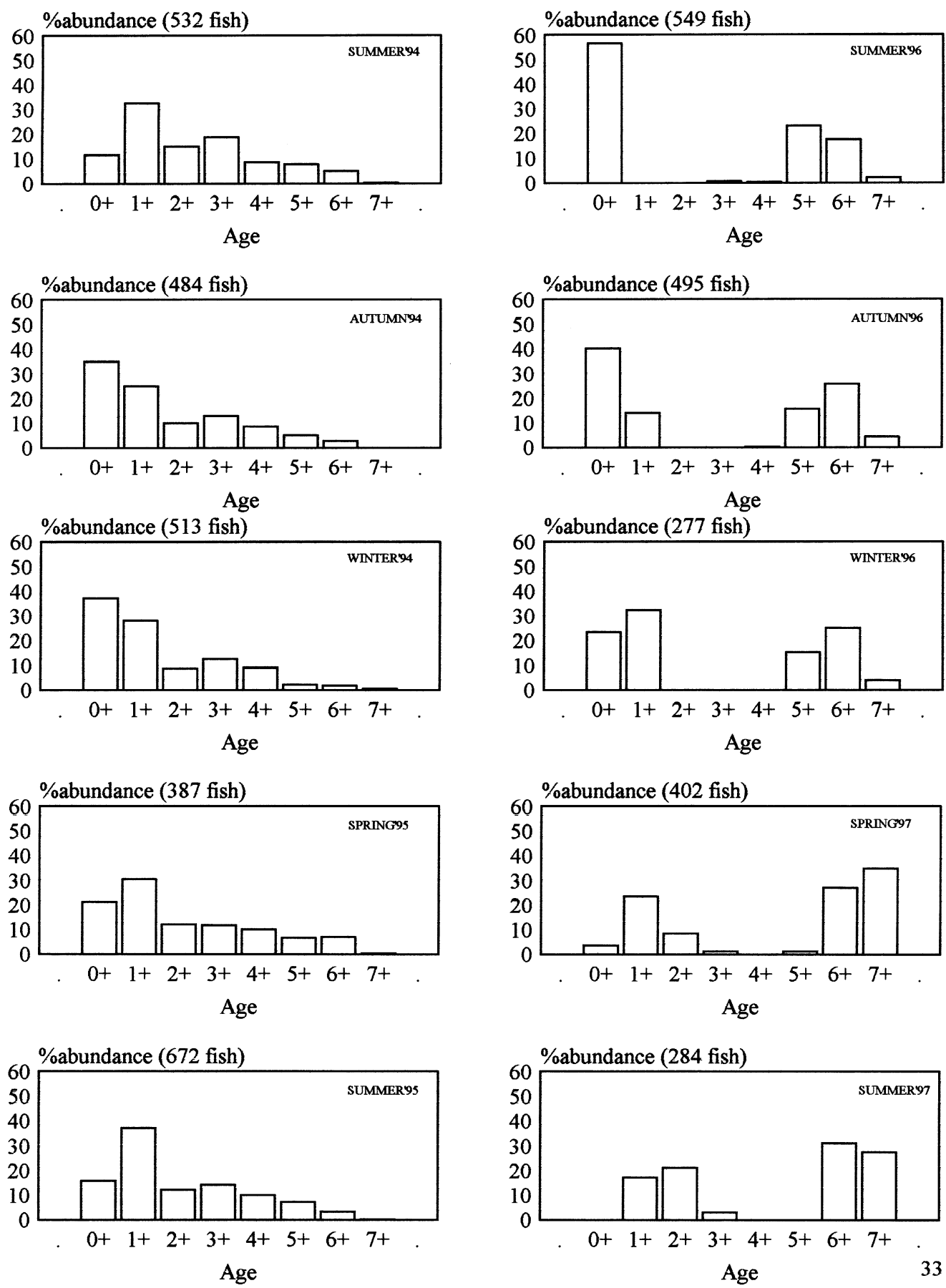

Figure 4. Frequency histogram of the percentage of abundance by age classes of the population of L. pyrenaicus in the samplings made.

II), except for samplings in spring and summer 1997 which form group III (figure $5 b$ ). Two population structures, one corresponding to the drought and the other to the rainy period, were defined. The structures observed for spring and summer 1997 do not correspond to either period. 

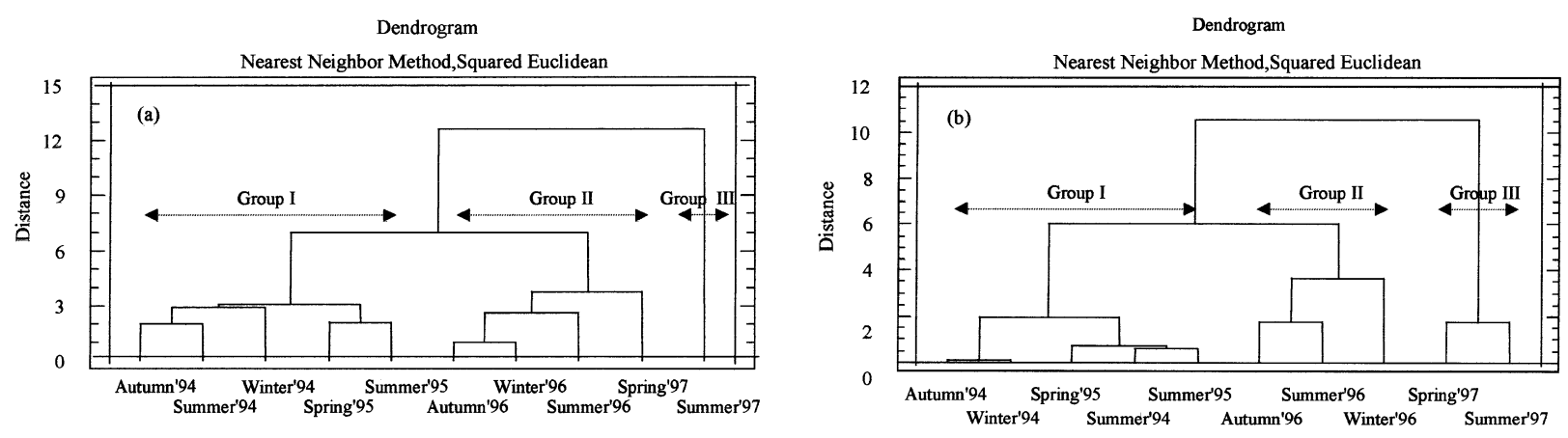

Figure 5. Cluster analysis revealing the structures by age classes of the two predominant populations, defined for the drought period and the rainy period: (a) B. sclateri, (b) L. pyrenaicus.

\subsection{Density and biomass}

The capture data, density, standing crop and capturability of the different populations by sampling season are shown in tables III-VI. The capturability in the predominant populations was constant during the sampling (test $\chi^{2}, P<0.05$ ), which enables reliable abundance estimates to be made.

The estimated average density of the total fish community (all species) was $25308 \mathrm{fish} \cdot \mathrm{ha}^{-1}$, the lowest in summer 1997 with 16504 fish.ha ${ }^{-1}$, and the highest in summer 1995 with $41837 \mathrm{fish} \cdot \mathrm{ha}^{-1}$. The average density during the drought was 30904 and $19711 \mathrm{fish} \cdot \mathrm{ha}^{-1}$ during the rainy period, which represents a decrease of $36.2 \%$ in overall density.

The average biomass of the fish community (all species) was $414.56 \mathrm{~kg} \cdot \mathrm{ha}^{-1}$, the lowest in winter 1994 with $183.85 \mathrm{~kg} \cdot \mathrm{ha}^{-1}$ and the highest in spring 1997 with $718.16 \mathrm{~kg} \cdot \mathrm{ha}^{-1}$. The average biomass during the drought was $386.42 \mathrm{~kg} \cdot \mathrm{ha}^{-1}$ and during the rainy period $442.7 \mathrm{~kg} \cdot \mathrm{ha}^{-1}$, representing an increase of $14.6 \%$ in overall biomass.

During the period of drought, these variables for the community of all four species, as well as for the populations of $B$. sclateri and $L$. pyrenaicus individually, presented maximum values in the samplings of summer, and a decrease in the autumn and winter samplings. But this pattern disappeared in the samplings of the rainy period.

The populations of $B$. sclateri and L. pyrenaicus were predominant in both density and biomass, together accounting for more than $90 \%$. During the drought, L. pyrenaicus was predominant in density, whereas $B$. sclateri was predominant in biomass. $B$. sclateri represented $34.3 \%$, and L. pyrenaicus $60.9 \%$ of average density during this period, while in respect to average biomass, $B$. sclateri represented $72.2 \%$ and L. pyrenaicus $26.8 \%$. During the rainy period, the situation changed drastically: there were significant decreases in the average proportions represented by $B$. sclateri, which fell by $41.5 \%$ in density and by $42.6 \%$ in biomass, whereas L. pyrenaicus increased by $19.1 \%$ in density and by $116.2 \%$ in biomass. $L$. pyrenaicus was predominant in the assemblage in terms of both density and biomass.

\section{DISCUSSION}

Many existing studies confirm that the most important factor affecting population distribution in rivers is the rate of flow $[10,11,18]$; these studies have opened lines of innovative research in rivers with substantial seasonal variation in flow and those subject to flooding $[5,6,19-22,25,28]$. Changes in water volume can affect the size distribution of fish populations [10, 18] and a considerable decrease in population density after flooding and overflowing has been observed associated with an increase in biomass $[4,11,17]$.

Observations in the Palancar stream are clearly similar to those in the previous studies. The decrease in the density of the total fish community was $36.2 \%$, while the increase in biomass was $14.6 \%$, when comparing the drought with the subsequent rainy period. Without doubt, the environmental factor producing these changes was the change in water volume. After five years of persistent dry conditions or drought, from 1990 to 1995, the subsequent heavy precipitations caused frequent flooding; for several weeks in the autumn and winter of the years 1995 and 1996, the stream overflowed its banks. The high flow rate washed downstream considerable amounts of material, and thus probably dispersed the fish populations downstream as well.

During the drought, the density and biomass of the fish populations varied in relation to the water flow 
Table III. Population characteristics of B. sclateri. Number of specimens captured in each catch or removal $\left(C_{i}\right.$, numerator) and standing crop (g) ( $W_{i}$, denominator), obtained by successive removal by electrofishing method. $C$ and $W_{t}(\mathrm{~g})$ are the total number and standing crop, respectively, of the sampling. $N$ is the estimated abundance with $95 \% C L$ and $B(\mathrm{~g})$ is the estimated standing crop. $N^{*}\left(\mathrm{fish} \cdot \mathrm{ha}^{-1}\right)$ and $B^{*}\left(\mathrm{~kg} \cdot \mathrm{ha}{ }^{-1}\right)$ are the density and biomass calculated. $p$ is catch efficiency, $\chi^{2}$ is the statistic of the Zippin model, and $r$ is the $P$-value for this test (minimum at $P<0.05$ ).

\begin{tabular}{lcccccccccccc}
\hline Sampling & $C_{1} / W_{1}$ & \multicolumn{1}{c}{$C_{2} / W_{2}$} & $C_{3} / W_{3}$ & $C / W$ & $N$ & $95 \% C L$ & $B$ & $N^{*}$ & $B^{*}$ & $p$ \\
\hline Summer'94 & $188 / 7295.83$ & $74 / 3115.51$ & $41 / 1310.72$ & $303 / 11722.04$ & 331 & 9.53 & 12805.28 & 11928 & 461.45 & 0.558 & 1.445 & 0.485 \\
Autumn'94 & $108 / 2610.35$ & $35 / 1018.04$ & $23 / 684.94$ & $166 / 4313.33$ & 178 & 5.91 & 4625.14 & 6414 & 166.67 & 0.587 & 3.159 & 0.206 \\
Winter'94 & $111 / 1464.16$ & $62 / 477.56$ & $50 / 338.25$ & $223 / 2279.97$ & 306 & 31.4 & 3128.56 & 11027 & 112.74 & 0.352 & 1.475 & 0.478 \\
Spring'95 & $145 / 4649.42$ & $62 / 2250.21$ & $23 / 553.4$ & $230 / 7453.03$ & 245 & 6.38 & 7939.72 & 8829 & 286.12 & 0.601 & 0.219 & 0.896 \\
Summer'95 & $177 / 5622.33$ & $89 / 1820.93$ & $69 / 1169.51$ & $335 / 8612.77$ & 427 & 27.5 & 10978.07 & 15387 & 395.61 & 0.400 & 2.916 & 0.232 \\
Summer'96 & $25 / 1033.13$ & $11 / 435.46$ & $11 / 468.71$ & $47 / 1937.3$ & 59 & 9.87 & 2431.93 & 2126 & 87.64 & 0.405 & 1.547 & 0.461 \\
Autumn'96 & $45 / 2505.71$ & $24 / 1043.05$ & $22 / 972.7$ & $91 / 4521.46$ & 127 & 21.7 & 6310.17 & 4577 & 227.39 & 0.341 & 1.331 & 0.514 \\
Winter'96 & $53 / 1736.59$ & $51 / 212.62$ & $22 / 130.85$ & $126 / 2080.06$ & 181 & 28.5 & 2988.02 & 6522 & 107.68 & 0.326 & 4.643 & 0.098 \\
Spring'97 & $36 / 2677.56$ & $18 / 3453.51$ & $4 / 514.01$ & $58 / 6645.08$ & 60 & 2.42 & 6874.0 & 2162 & 247.72 & 0.644 & 1.669 & 0.431 \\
Summer'97 & $83 / 3363.94$ & $19 / 1777.12$ & $9 / 864.73$ & $111 / 6005.79$ & 113 & 2.01 & 6114.0 & 4072 & 220.32 & 0.721 & 1.753 & 0.416 \\
\hline
\end{tabular}

Table IV. Population characteristics of L. pyrenaicus (symbols as in table III).

\begin{tabular}{lcccccccccccc}
\hline Sampling & $C_{1} / W_{1}$ & $C_{2} / W_{2}$ & $C_{3} / W_{3}$ & $C / W$ & $N$ & $95 \% C L$ & $B$ & $N^{*}$ & $B^{*}$ & $p$ & $\chi^{2}$ & $r$ \\
\hline Summer'94 & $232 / 1849.4$ & $160 / 987.4$ & $58 / 381.91$ & $450 / 3218.71$ & 532 & 21.0 & 3758.27 & 19171 & 135.43 & 0.463 & 2.060 & 0.360 \\
Autumn'94 & $89 / 324.18$ & $66 / 191.18$ & $62 / 133.75$ & $217 / 649.11$ & 484 & 152.3 & 1447.78 & 17441 & 52.17 & 0.180 & 0.654 & 0.721 \\
Winter'94 & $91 / 255.91$ & $78 / 402.87$ & $62 / 167.01$ & $231 / 825.79$ & 513 & 155.3 & 1833.89 & 18486 & 66.08 & 0.181 & 0.087 & 0.957 \\
Spring'95 & $114 / 887.78$ & $85 / 635.17$ & $56 / 278.34$ & $255 / 1801.29$ & 387 & 49.8 & 2733.72 & 13945 & 98.51 & 0.301 & 0.224 & 0.890 \\
Summer'95 & $157 / 1227.58$ & $118 / 715.41$ & $94 / 233.51$ & $369 / 2176.5$ & 672 & 110.1 & 3963.7 & 24216 & 142.83 & 0.233 & 0.076 & 0.962 \\
Summer'96 & $155 / 2846.0$ & $97 / 940.0$ & $86 / 422.0$ & $338 / 4208.0$ & 549 & 72.83 & 6835.42 & 19784 & 246.32 & 0.273 & 2.070 & 0.355 \\
Autumn'96 & $180 / 2028.44$ & $101 / 1049.44$ & $80 / 447.83$ & $361 / 3525.71$ & 495 & 39.75 & 4834.42 & 17838 & 174.21 & 0.352 & 2.085 & 0.352 \\
Winter'96 & $124 / 2067.04$ & $78 / 536.83$ & $33 / 197.13$ & $235 / 2801.0$ & 277 & 1494 & 3301.6 & 9982 & 118.98 & 0.465 & 1.785 & 0.409 \\
Spring'97 & $66 / 1702.0$ & $52 / 2310.68$ & $48 / 1365.19$ & $166 / 5377.87$ & 402 & 165.4 & 13023.52 & 14486 & 469.32 & 0.163 & 0.247 & 0.883 \\
Summer'97 & $147 / 4087.37$ & $83 / 2487.7$ & $27 / 794.36$ & $257 / 7369.43$ & 284 & 9.74 & 8143.65 & 10234 & 293.46 & 0.541 & 3.387 & 0.184 \\
\hline
\end{tabular}


Table V. Population characteristics of $C$. paludica (symbols as in table III). * The correlation coefficients $(r$ ) for these relationships were not significant (minimum at $P<0.001$ ).

\begin{tabular}{lcccccccccccc}
\hline Sampling & $C_{1} / W_{1}$ & \multicolumn{1}{c}{$C_{2} / W_{2}$} & \multicolumn{1}{c}{$C_{3} / W_{3}$} & \multicolumn{1}{c}{$C / W$} & $N$ & $95 \% C L$ & $B$ & $N^{*}$ & $B^{*}$ & $p$ & $\chi^{2}$ & $r$ \\
\hline Summer'94 & $5 / 3.63$ & $5 / 13.31$ & $5 / 6.47$ & $15 / 23.41$ & 41 & 70.0 & 63.98 & 1477 & 2.3 & 0.139 & 0.232 & 0.890 \\
Autumn'94 & $13 / 37.94$ & $5 / 8.46$ & $4 / 4.51$ & $22 / 50.91$ & 24 & 2.9 & 55.54 & 865 & 2 & 0.537 & 0.716 & 0.690 \\
Winter'94 & $31 / 77.68$ & $14 / 26.55$ & $9 / 19.35$ & $54 / 123.58$ & 61 & 5.58 & 139.59 & 2198 & 5.03 & 0.505 & 0.384 & 0.825 \\
Spring'95 & $9 / 14.07$ & $5 / 7.34$ & $5 / 7.31$ & $19 / 28.72$ & 25 & 8.22 & 37.79 & 901 & 1.36 & 0.365 & 0.594 & 0.740 \\
Summer'95 & $13 / 15.44$ & $11 / 29.53$ & $9 / 15.29$ & $33 / 60.26$ & 62 & 36.88 & 113.22 & 2234 & 4.07 & 0.221 & 0.105 & 0.948 \\
Summer'96 & $7 / 8.72$ & $1 / 0.32$ & $2 / 0.56$ & $10 / 9.6$ & 10 & 0.85 & 9.6 & 360 & 0.35 & 0.667 & 2.844 & 0.241 \\
Autumn'96 & $1 / 7.53$ & $4 / 1.24$ & $9 / 9.50$ & $14 / 18.27$ & 14 & $*$ & 18.27 & 504 & 0.66 & 0.012 & 7.252 & $0.026^{*}$ \\
Winter'96 & $10 / 5.13$ & $17 / 9.86$ & $7 / 9.22$ & $34 / 24.21$ & 75 & 59.22 & 53.40 & 2703 & 1.92 & 0.181 & 4.545 & 0.100 \\
Spring'97 & $17 / 19.55$ & $3 / 1.82$ & $6 / 7.54$ & $26 / 28.91$ & 28 & 2.85 & 31.13 & 1009 & 1.12 & 0.553 & 5.112 & 0.077 \\
Summer'97 & $23 / 37.41$ & $18 / 32.66$ & $2 / 4.05$ & $43 / 74.12$ & 43 & 3.10 & 74.12 & 1549 & 2.97 & 0.581 & 6.200 & $0.045^{*}$ \\
\hline
\end{tabular}

rate; the maximum values of these variables are found in summer, the minimum values in autumn and winter, following the scarce precipitations. In summer, the drop in the flow rate is very marked, and flow even dries up in areas downstream of the sampling section. When this happens the fish near the headwaters seek more favourable environmental conditions, thus producing the observed increases in density and biomass. Following the autumn rains and the restoration of the normal flow rates, the fish are more dispersed, leading to a decrease in these two variables.

When the rainy period arrives, the relationship between the seasonal variations in flow rate and the density and biomass of the fish populations is not so clear. During the course of the second cycle of the study period, the flow continued to vary seasonally but did not dry up completely in the summer, thus an increase in these variables is not observed. The dispersion of the fish with the flooding modified the structure of the populations: this comprised mainly adult individuals capable of overcoming the flow and tolerating high water velocities, together with juveniles born the previous spring.

It is notable that, during spring, with the decrease in density there is a corresponding increase in biomass. This must be due to the physiological changes in the fish that take place during this period, such as gonad development and an increase in food intake, with subsequent fattening of the fish $[29,30]$.
In the population of $B$. sclateri during the drought, the predominant age classes were $0+, 2+$ and $4+$, with proportions of the total exceeding $15 \%$, corresponding to the cohorts of 1994, 1992 and 1990. These results suggest that the study zone constitutes the reproduction and nursery area for the population. The situation in the following rainy period seems to confirm this hypothesis, since at this time the age classes predominant in the sampling area are $0+$ (alevins) and the intermediate classes, $6+, 7+$ and $8+$ (those of reproduction age). These intermediate age classes, of $5+$ to $8+$, are the ones that contribute most in percentage terms by age class, to fecundity; and the reproductive effort of females during the spawning period reaches its maximum values at age class $7+[29,30]$. The situation observed in the summer of 1997, with the almost complete disappearance of individuals of age class $0+$ does not invalidate this conclusion: the explanation for this is the presence of the largemouth bass. In the analysis of the gastrointestinal contents of the eighteen specimens of this species captured, a total of fourteen fishes of the species $B$. sclateri and $L$. pyrenaicus of lengths between 14 and $58 \mathrm{~mm}$ were found; this length interval corresponds to alevins and juveniles of these species. Bearing in mind that the samplings were conducted at regular seasonal intervals and given the ratio between number of prey and number of largemouth bass predators, it is easy to comprehend the dimension of the ecological disaster

Table VI. Population characteristics of M. salmoides (symbols as in table III). B was measured in the laboratory.

\begin{tabular}{lccccccccccccc}
\hline Sampling & $C_{1} / W_{1}$ & $C_{2} / W_{2}$ & $C_{3} / W_{3}$ & $C / W$ & $N$ & $95 \% C L$ & $B$ & $N^{*}$ & $B^{*}$ & $p$ & $\chi^{2}$ & $r$ \\
\hline Summer'97 & $14 / *$ & $4 / *$ & $0 / *$ & $18 / 381.98$ & 18 & 0.69 & 381.98 & 649 & 13.76 & 0.818 & 0.709 & 0.701 \\
\hline
\end{tabular}


for the native populations represented by the presence of this piscivorous species in the Palancar stream.

This situation is reflected in the cluster analysis where the sampling of summer 1997 was left isolated from the group corresponding to the rainy period. The drastic reduction in individuals of age class $0+$ differentiates the population structure of this sampling from the rest of the rainy period samples.

Similarly, in the case of $L$. pyrenaicus where the predominant age classes are $0+$ and $1+$, this situation is not changed following the rains. In the samplings of summer, autumn and winter of 1996, the age class $0+$ continues to be predominant, while at the same time, the age classes $5+$ and $6+$ take on greater importance. In other words, the predominant age classes are again the alevins and those of reproduction age. For this population, the age class contributing most to total fecundity and making the greatest reproductive effort is 5+, with successive ages showing diminishing importance [29, 30].

The presence of the largemouth bass has also affected this population; in summer 1997, not a single individual of age class $0+$ was captured. Moreover, at least four of the fish prey of this species found in the stomachs of the largemouth bass analysed were of age classes $1+$ and $2+$. This is the reason why the cluster analysis found that samplings made in spring and summer 1997 were isolated from the group corresponding to the earlier part of the rainy period. The disappearance of individuals of age class $0+$ (total disappearance in summer and almost total, to only $3.6 \%$, in spring) differentiates the population structure from that found earlier.

\section{CONCLUSION}

Four general conclusions can be drawn from these results.

- Without a doubt, precipitation is the most important of the many abiotic factors that regulate the dynamics of the fish populations of the Palancar stream. All the most evident changes occurred when the period of drought had ended.

- During the drought, the most important factor is the marked seasonality of the water flow, resulting from the lack of precipitation typical of the climate of the area in which the study zone is located.

- During the rainy seasons (autumn and winter), the section of stream studied constitutes the reproduction and nursery area of the fish populations, since individuals of reproduction age and alevins are predomi- nant. It can thus be concluded that reproduction is the main biotic factor regulating the population dynamics in this season.

- Lastly, the presence of the largemouth bass is a factor that is going to alter the natural dynamics of the fish populations in the Palancar stream. The future development of these populations is uncertain but clearly negative.

The results of this study, conducted as part of a broader project of national scope on the rivers of the whole Iberian Peninsula, provide a valuable contribution to knowledge of the dynamics of fish populations in rivers and streams of Mediterranean character, since the findings show how in this type of ecosystem, density and biomass fluctuate naturally in short periods of time. Understanding this dynamic is fundamental for the correct management of river fish, particularly when preparing plans for re-population. Such measures are frequently part of more general environmental recovery plans following the construction of hydraulic infrastructure installations, roads, the discharge of toxic waste, etc., and must be based on sound knowledge carefully applied, to avoid inappropriate action.

In respect to the introduction of exotic species, a prior evaluation and subsequent monitoring are particularly important, since their indiscriminate release may have very negative effects. Information campaigns on this subject, directed at anglers and organisations involved with sports fishing who are thought to be those mainly responsible for such introductions, are considered necessary.

Acknowledgments. This study was funded by the DGICYT (Spain), project No. PB92-0093 and by a grant from the 'Fundación Caja' de Madrid. The authors would also like to thank members of the research team of Fish Population Dynamics (RNM 243, Cadiz University) for their help with the field work. Thanks are also extended to Miriam Hampel and Royston F. Snart for their help in preparing the English version of the manuscript. Lastly, we are grateful for the valuable comments of the two anonymous referees and the Editor, Mr Joao Marques, who reviewed the original manuscript.

\section{REFERENCES}

[1] Bain M.B., Finn J.T., Booke H.E., Streamflow regulation and fish community structure, Ecology 69 (1988) 382-392.

[2] Blanco J.C., González J.L., Libro Rojo de los Vertebrados de España, Ministerio de Agricultura, Pesca y Alimentación, ICONA, 1992.

[3] Boulton A., Lake P.S., Australian temporary streams - some ecological characteristics, Verh. Int. Ver. Limnol. 23 (1988) 1380-1383. 
[4] Cihar J., The effect of flood upon the fish fauna of the Mnichovka Brook near Senohraby, Ecological Fish Production in the Inland Delta of the Middle Danube, a Floodplain River, in: Holčík J.P. (Ed.), Environ. Biol. Fishes 46 (1996) 151-165.

[5] Crisp D.T., Mann R.H.K., Cubby P.R., Effect of the regulation of the River Tees upon fish populations below Cow Green reservoir, J. Appl. Ecol. 20 (1983) 371-386.

[6] Crisp D.T., Mann R.H.K., Cubby P.R., Effect of impoundment upon fish populations in afferent streams at Cow Green reservoir, J. Appl. Ecol. 21 (1984) 739-756.

[7] Giudicelli J.M., Dakki M., Dia A., Caractéristiques abiotiques et hydrobiologiques des eaux courantes méditerranéennes, Verh. Int. Ver. Limnol. 22 (1985) 2094-2101.

[8] Herrera M., Fernández-Delgado C., The life-history of Barbus bocagei sclateri (Günther, 1868) in a tributary stream of the Guadalquivir River basin, southern Spain, Ecol. Freshwat. Fish. 1 (1992) 42-51.

[9] Herrera M., Hernando J.A., Fernández-Delgado C., Bellido M., Age, growth and reproduction of the barbel, Barbus sclateri (Günther, 1868) in a first-order stream in southern Spain, J. Fish Biol. 33 (1988) 371-381.

[10] Holčík J., The influence of hydrological regime and water temperature upon the activity and density of fish populations in the anabranches of the Danube River, Pr. Ústavu Rybárstva Hydrobiol. 6 (1987) 33-58.

[11] Holčík J., Ecological fish production in the inland delta of the Middle Danube, a floodplain river, Environ. Biol. Fishes 46 (1996) 151-165.

[12] Magalhães M.F., Effects of season and body-size on the distribution and diet of the Iberian chub Leuciscus pyrenaicus in a lowland catchment, J. Fish Biol. 42 (1993) 875-888.

[13] Mahon R., Accuracy of catch-effort methods for estimating fish density and biomass in streams, Environ. Biol. Fishes 5 (1980) 343-360.

[14] Mahon R., Balon E.K., Noakes D.L.G, Distribution community structure and production of fishes in the upper Speed River, Ontario: a pre-impoundment study, Environ. Biol. Fishes 4 (1979) 219-244.

[15] Maitland P.S., Crivelli A.J., Conservation of freshwater fish. Arles: Tour du Valat, Effect of River Regulation on the Life-History Patterns of Barbus sclateri in the Segura River Basin (South-East Spain), in: Torralva M.M., Puig M.A., Fernández-Delgado C. (Eds.), J. Fish Biol. 51 (1997) $300-311$.

[16] Mollá S., Maltchik L., Casado C., Primeros datos sobre el metabolismo de un arroyo temporal mediterráneo de Sierra Morena (Córdoba), Limnética 10 (1994) 59-67.

[17] Onodera K., Ueno T., On the survival of trout fingerling stocks in a mountain brook. II. Survival rate measured and scouring effect of flood as a cause of mortality, Bull. Jap. Soc. Sci. Fish. 27 (1961) 530-557.

[18] Paulov D.S., The biological basis of fish behaviour control in a water flow, Ecological Fish Production in the Inland Delta of the Middle Danube, a Floodplain River, in: Holčík J.P. (Ed.), Environ. Biol. Fishes 46 (1996) 151-165.

[19] Penczak T., Molinski M., Fish production in Oued Sebaou, a seasonal river in North Algeria, J. Fish Biol. 25 (1984) 723-732.

[20] Penczak T., Romero T.E., Accuracy of modified catch-effort method for estimating fish density in large rivers (Warta River,
Poland), in: Cowx I.G. (Ed.), Developments in Electric Fishing, Fishing News Books, Oxford, 1990, pp. 191-196.

[21] Penczak T., Galicka W., Koszalinski H., Fish populations density and biomass in the Warta River: pre-and postimpoundment study, Acta Univ. Lodziensis Folia Limnol. 5 (1991) 59-77.

[22] Penczak T., Pietrowska M., Galicka W., Density, growth and diet of predatory fish in the Warta River: post-impoundment study, Acta Univ. Lodziensis, Folia Limnol. 5 (1991) 101-122.

[23] Platts W.S., Megahan W.F., Minshall G.W., Methods for evaluating stream, riparian, and biotic conditions, Gen. Tech. Rep. INT-138, Odgen, V.T. USDA, Forest Service, Intermountain and Range Experiment Station, 1983.

[24] Rodriguez-Ruiz A., Granado-Lorencio C., Spawning period and migration of three species of cyprinids in a stream with Mediterranean regimen (SW Spain), J. Fish Biol. 41 (1992) 545-556.

[25] Ross S.T., Mathews W.J., Echelle A.A., Persistence of stream fish assemblages: effects of environmental change, Am. Nat. 126 (1985) 24-40.

[26] Ryder G.I., Scott D., The applicability of the river continuum concept to the New Zealand streams, Verh. Int. Ver. Limnol. 23 (1988) 1441-1445.

[27] Saila S.B., Recksick C.W., Prager M.H., Basic Fishery Science Programs. A Compendium of Microcomputer Programs and Manual of Operation, Elsevier, 1988.

[28] Schlosser I.J., Environmental variation, life history attributes, and community structure in stream fishes: implications for environmental management and assessment, Environ. Manag. 14 (1990) 621-628.

[29] Soriguer M.C., Ciclos de vida y ecología trófica de los peces del río Palancar (Sierras Subbéticas de Córdoba), Doctoral thesis, University of Córdoba, 1996.

[30] Soriguer M.C., Bravo R., Vallespín C., Gómez-Camas C., Hernando J.A., Reproductive strategies of two species of cyprinids in a stream with Mediterranean regimen (SW Spain), Arch. Hydrobiol. 148 (2000) 119-134.

[31] Torralva M.M., Puig M.A., Fernández-Delgado C., Effect of river regulation on the life-history patterns of Barbus sclateri in the Segura river basin (south-east Spain), J. Fish Biol. 51 (1997) 300-311.

[32] Vannotte R.L., Minshall G.W., Cummins K.W., Sedell J.R., Cushing C.E., The River Continuum Concept, Can. J. Fish. Aquat. Sci. 37 (1980) 103-137.

[33] Vidal-Abarca M.R., Montes C., Suarez M.L., RamírezDíaz L., An approach to the ecological characterization of arid and semiarid basins, GeoJournal 26 (1992) 335-340.

[34] Watson D.J., Balon E.K., Determination of age growth in stream fishes of northern Borneo, Environ. Biol. Fishes 13 (1985) 59-70.

[35] Winterbourn M.J., Rounick J.S., Collier K.J., Are New Zealand stream ecosystems really different? N. Z. J. Mar. Freshw. Res. 15 (1981) 321-328.

[36] Winterbourn M.J., Collier K.J., Graesser A.K., Ecology of small streams on the west coast of the South Island, New Zealand, Verh. Int. Ver. Limnol. 23 (1988) 1427-1431.

[37] Zippin C., An evaluation of the removal method of estimating animal populations, Biometrics 12 (1956) 163-189.

[38] Zippin C., The removal method of population estimation, J. Wildl. Manag. 22 (1958) 82-90. 